\title{
Greenwashing and Cleaning
}

\author{
Develter Dirk ${ }^{1}$ and Malaise Peter ${ }^{2}$ \\ ${ }^{1}$ Ecover Coordination Center NV, \\ ${ }^{2}$ Meta Fellowship npo \\ Belgium
}

\section{Introduction}

The world population is rapidly growing: estimates tell us that from nearly seven billion actually, we're on our way to some eight to ten billion in 2050 (US Census Bureau, 2011). This ongoing growth generates a forever growing demand in products and services: raw materials, energy, transport and transformation capacity, waste disposal. Unfortunately, the backbone of all of these activities is mainly dependent of a single fossil source, crude oil and its derivatives. However, these have a double disadvantage:

- crude oil is only present in geographically limited areas of the planet

- the stock of reasonably accessible fossil matter is, after 180 years of industrial life, nearly depleted and cannot be replenished

Parallel to this huge growth and rapid depletion there is a growing consciousness on hygiene and personal deployment in all countries worldwide, but mainly in developing ones. The need for products and services is still growing exponentially.

Basically, this complex growth is already transcending the capacity of the planet, making the largest part of the average economic activities unsustainable. Some market segments already suffer from it, metals e.g.: prices for ores and metals have rocketed the last couple of years and the market for recycled materials is on an all time high. For some of them we are quite close to a shortage. It won't stop there: with decreasing mineral and fossil sourcing capabilities, producers will be forced to turn to non-fossil, non-mineral, renewable sources, that means in the first place plant sources and to a lesser extent, animal sources.

These raw material sources are actually and nearly exclusively the providers of food, but they will inevitably suffer a strong competition from non-food production demand. We already saw the consequences of unplanned and unregulated behavior on the matter when, in 2007, there was a sudden huge demand in renewable raw materials for the production of biofuel, the "Food vs. Fuel" crisis, also called the "Tortilla Flap". Tortilla prices doubled for the already poor Mexican population, causing riots. The real causes were not even a raw material shortage, but mainly speculations in the globalised markets (Kaufman, 2010; Nelson, 2008; Western Organisation of Resource Councils, 2007).

When one day, next to food, a large part of clothing, housing and utensils will forcedly have to be derived from plant and animal sources, there will not only be substantial shortages, 
high prices, fights and even wars to be expected in relation to those materials, but it will simply be impossible to generate such an amount of raw materials on this planet. At the actual consumption rate, available agricultural space is simply not big enough to provide all the necessary. The only reasonable outcome is a double action. We must at the same time substantially reduce our needs in raw materials and energy, and hugely increase research in new ways of raw material sourcing, higher efficiency and better transformation processes.

Such a type of development has already been proposed and documented by the Wuppertal Institute (http://www.wupperinst.org), Germany, under the names of "Factor Four" and "Factor Ten", targeting a fourfold, respectively tenfold reduction in the bulk of our needs. Their theme is still: "We use resources as though we had four earths at our disposal", which describes the actual problem quite well. The Wuppertal Institute also developed instruments to quantify such developments, amongst them the Material Input Per Service tool (MIPS). This approach measures how much earthly substance is needed to generate all the necessary for one service of a given product.

As always with such developments we can discuss until Doomsday if this is the right thing to do here and now and if there are no better solutions (read: less compulsory, less drastic, financially cheaper etc.). Perhaps - but can we afford to wait? Do we really have the time to abide such ideal solutions? We, the authors, are convinced we don't and we prefer in this to marry the approach of the Swedish 'Natural Step' organization (http://www.naturalstep.org): let's not be stuck on endless discussions about the twigs of problems, but let's agree about the trunk and the branches.

\section{Global pollution consequences}

One of the main consequences of unsustainable economical activities is the continuous exposure of man to man-made chemicals, and to high levels of mixed, persistent pollution. Especially children, young people and the elderly are vulnerable. It's not that much the spectacular catastrophes, such as oil spills and sinking tankers, which are quite visible; but the silent, insidious spreading of chemicals that should not reside in nature at all. Heavy metals are notorious, but there are even more risky compounds, such as:

- $\quad$ pesticides and insecticides, for which Rachel Carson warned us as early as 1960 in her book Silent Spring

- $\quad$ PCB's and CFC's, as representatives of a huge family of chlorinated compounds

- preservation and disinfecting agents

- $\quad$ historical polluters set free by the meltdown of glaciers and polar caps

All of the consequences become only indirectly visible, through degrading biodiversity and fertility, making species disappear at an abnormal rate and speed, through high incidences of uncommon pathologies or even through the transmission of risky genetic properties. Unfortunately, economists and investors don't see these phenomena as relevant for economic life. It's true that when economic life is just looking at the next fiscal quarter, hardly anything is relevant. When our ancestors would have thought and acted like that, we wouldn't be here.

But there is a relationship with those phenomena - and a tight one too. One out of many immediate consequences of man-made pollution for example is the actual worldwide 
mortality amongst honey bees. Hardly noticed by most people but for their honey we consume, they are primarily responsible for pollination in nature. A declining pollination will, amongst others, have an immediate negative influence on agriculture and everything depending on it, but also on pollination in the wild. This will at the end turn the planet into an infertile, uneconomic desert.

\section{Unsustainable processing}

The production processes for most goods and services are mainly using unsustainable energy, involve unsustainable processing techniques, unsustainable transport methods and generate an unacceptable amount of problematic waste. Only very few countries have managed to switch a substantial part of their energy production to sustainable energy sources. Some of the actions that have been taken on the matter are questionable, because they only touch a small part of the problem. Saving bulbs are such an example: they leave about $81 \%$ of the household consumption of electricity with fossil sources and make the consumer believe that he is solving a problem. Politically spoken the venue of saving bulbs was a quick and dirty decision, but in the meantime new health concerns have risen in relation to saving bulbs. Unfortunately, they are now becoming compulsory in many countries. We don't hear anything though on saving fridges, saving deep freezers, saving washing machines, saving dry tumblers, saving fryers, saving stoves; all of these devices are in their actual form the real culprits, counting for $81 \%$ of the energy consumption in households.

Saving cars exist to some extent: the hybrids are on sale since some years and some prototypes of electric cars are presented increasingly. However, their promotion is not taken serious enough, neither by their producers, nor by politicians. Most cars still have fuel consumption and $\mathrm{CO}_{2}$ emission rates which are unacceptably high, although the improvement technology is available. Some car companies are known to actively lobby against stricter emission laws (Greenpeace, 2011). Public transport offers an interesting solution to a large part of the private traffic, but it is actually legging far behind as to comfort, frequency and efficiency. It will nevertheless be one of the main choices to realize a sustainable transport system for future society.

When we look at production processes the situation is even worse. Up to recently there was hardly any attention for sustainable industrial processing techniques. More or less as a rule such processes involve high temperature and high pressure, often accompanied by other energy demanding techniques such as vacuum generation, freezing or desiccation. The production and transformation of aluminum or the cracking of crude oil and the processing of many of their derivatives e.g., are such energy devouring activities. Some other sectors such as the production of chemicals for household and industrial uses can cause huge environmental and health problems. Hopefully we will not forget Bhopal (India), still an unsolved problem for the local victims, 20 years after the catastrophy occurred. Nor more recently the Deepwater Horizon (Mexico) and Ganeth Alpha (Aberdeen) ridge oil spills and the flood of poisonous aluminum sludge in the Ajkai Timföldgyár factory (Ajka, Hungary). These are just a few examples of the consequences of unsustainable production methods.

The production of commodities for the mass market is equally tainted. Detergents and their raw materials are for the essential part made from fossil sources, although they could easily be made from renewables - as a matter of fact they have been, up to about 1930. A large part 
of paper derived disposables still use freshly cut trees instead of recycled fibers. In many countries industries get an explicit advantage on their electricity bill because of their high consumption - whereas the opposite should be the case when we would apply the rule 'the pollutor pays'. There is hardly an incentive for companies to take serious action on the matter.

Production processes in the agricultural realm have, on top of high energy demands in some sectors, such as greenhouses, a huge impact on health and environment through the chemicals they introduce in the food web: synthetic fertilizer, insecticides and pesticides, as well as aftertreatments for preservation and pest control. Potato culture knows an average of about 11 chemical treatments before harvesting. The production and use of banana pesticides and insecticides causes heavy health and environmental impacts (Chua, 2007). Soy production for animal feedstock, and palm oil production for food and non-food applications, are still devastating huge areas of virgin forest, destroying important natural $\mathrm{CO}_{2}$ dumps.

The policy of subsidizing agricultural and other produce for export are still in place, even for such goods that can easily be produced in the destination countries. There is no sensible reason why Austrians should eat Belgian green peas instead of the ones from their own agriculture, and Belgians the Austrian ones, unless in case of a shortage on either side. Consuming as much as possible produce and products from where one lives could substantially reduce primary fuel consumption, traffic jam, pollution and health impacts. Farmers should be subsidized for maintaining the natural fertility of the soil and the preservation of biodiversity - not for overproduction within monocultures, as it is the case now. That would lead to a broad support and promotion of certified organic farming, rather than fighting it with prejudice. Organic farming has maintaining the natural fertility and preserving biodiversity in its basic principles - you can't have organic farming without them. The secondary effects of such measures would in the middle and long term be very important as well: no synthetic fertilizer, little to no chemical insecticides and pesticides, a healthy soil and a healthier water system.

The professional transport of food and non-food commodities knows comparable problems. But there is in the transport sector even less interest for sustainable transport solutions than with individuals: maximum load, high speed and low financial cost are the sole drivers. Some isolated projects, such as the one set up by the Belgian distributor Colruyt with an innovative lorry, goes further and tries to reduce fuel consumption and emissions by proactively financing, testing and adopting hybrid equipment that will respond to the newest EU requirements (Colruyt Group, 2010).

For any man made activity we should since long have adopted the Precautionary Principle (European Commission, 2000): when we don't know the consequences, or have difficulties in estimating the extent of health and environmental impacts - including the depletion of raw material sources - we just shouldn't do it.

\section{Old stuff}

These facts are not new. Rachel Carson wrote her book Silent Spring in 1960 (Carson,1960). She warned for a thoughtless, large scale use of man made, highly effective chemicals and documented the then already visible consequences for health and environment. 
Starting in 1970, several high-level reports continued warning for the consequences of such an unsustainable development: The Predicament of Mankind (Christakis et al., 1970); Limits to Growth from the Club of Rome (Meadows et al., 1972); Our Common Future from the Brundtland Commission (World Commission on Environment and Development, 1987). But in spite of all these serious efforts and a series of follow-up initiatives such as the Rio Conference, Agenda 21, Rio+10 and many more, very little systematic action has been taken.

The global principle to tackle what became a global problem, is Sustainable Development. The Brundtland report, in which the term 'sustainable development' was first used, describes this in a much cited quote as "development that meets the needs of the present without compromising the ability of future generations to meet their own needs." It has three focus points, which are inextricably intertwined and should not be separated at any time:

- a social focus

- an economical focus

- an ecological focus

It will be obvious that each of these three members has its own specific rules and laws, which might be influenced by the others, but not overruled or replaced by them. It is not possible that economic principles will become more important than social or environmental ones; but they cannot become less important either. An essential fact - often misunderstood even by fervent followers - is that Sustainable Development is a life style, not a status that one can reach some time. You can't be, or can't become 'sustainable', there will always be a further stage of development to attend.

However, to cut short any misunderstanding: when we will in the following write about 'sustainable raw materials' or 'sustainable energy' we are not pointing at a status those items are supposed to be in, but at the whole process that leads to their existence. The raw material is a crystallization point of a generative process which fits - or doesn't fit, or only partially fits - into principles of Sustainable Development.

It's also obvious that, on the short term, it will not be possible to realize all elements of Sustainable Development to an equal degree of fulfillment, immediately and at the same time. Many things will only be partially realized through compromises between societal partners, in a slow process of involvement and comprehending.

Sustainable Development encompasses sustainable design, sustainable raw materials, sustainable production processes, sustainable energy and services, green taxes, as well as sustainable consumption. In short, it's a cradle-to-grave approach at all times and a cradle-tocradle approach whenever possible (more on this theme is to be found in Braungart and McDonough (2002). Cradle-to-grave means that all partners are part of the whole process, from the design of the product or service until the disposal of possible leftovers, and anything in between. Each step has to be optimized: it should involve the lowest amount of earthly substance and energy possible, have the highest efficiency and user friendliness possible and generate as little leftovers as feasible (that what we still call 'waste'). This should be featured without compromising elements such as the availability, the efficacy or the price of the product or service.

Cradle-to-cradle goes even a step further: whatever substance that is not fully destroyed at use (such as food), has to be made reusable for a similar, or even for a completely different 
application by similar or different producers. In doing so, 'waste' becomes non-existent, as it will be a raw material for a new process. This is the way nature acts, and nature is never short of raw materials, unless humans degrade its ways.

Can we secure such a development, such type of products and services, can we guarantee that this will work and that everything will be true and honest? No! One of the important elements to be redeveloped in parallel, is trust. Trust mustn't be blind, though; there are several mechanisms that can be put to work to coach Sustainable Development. Green Taxes are one of those, but they are sort of an end-of-pipe solution and they should preferably only be used as temporary, corrective measures. It makes no sense to implement such a huge beast as Sustainable Development by means of force. Another useful mechanism are Green Labels. We know a whole bunch of them all over the planet, they have since a couple of years grown like mushrooms, and not always for the good. Unfortunately these Green Labels have mostly been developed by an amalgamate of politics and industry, and we should not forget that this is the tandem that pushed us into Unsustainability. It's comparable to farmers and butchers deciding about the criteria for veggie burgers; that makes no sense, really.

When Green Labels have to play a proficient role - and we think they can and should - the consumers have to get far more grip on the process of green labeling, from designing over controlling to improving them. Politics can check their correct and equitable implementation, but should not decide on the content or the format. Industry has to listen to what the consumer wants, not enforce what they themselves want to produce and sell. When it goes like that, we end up with a mishap, such as the actual EU Ecolabel on detergents. It lacks all kinds of arms and legs: the raw material sourcing is evaluated on its ecological merits in a crippled way, there is no social element present in the model, product efficiency is stubbornly compared against conventional, thus unsustainable products (in other words: race car vs. bike). Very weird influencing from conventional industry circles crept in through doors and windows, and one of the consequences is that fragrances based on plants are in practice prohibited in ecolabeled products!

Public procurement is another extremely powerful mechanism to implement Sustainable Development. When all layers of public power should systematically include ecological and social criteria in their evaluations and tenders for products and services, and not just take the lowest price as a gauge, the usual product and service ranking might be turned upside down.

Companies and offices of all kinds can use the same strategy. New knowledge and understanding would be instilled slowly into society as a whole, because consumers would comprehend and follow the example.

Hovering back over what we wrote up to now, we can see that Sustainable Development is not just about some kind of environmental conservation, but clearly encompasses the economical, social and environmental issues we tried to describe.

\section{Washing and cleaning}

Why washing and cleaning? In the next two chapters we will mainly deal with ways to deploy, expand and improve the characteristics of Sustainable Development within commodity products and services, and the models used to do so. Both the authors have a longstanding experience in designing and modeling concepts, formulas and strategies for 
sustainable washing and cleaning products, as staff member and retired staff member with the worldwide market leader in the trade.

A traditional situation for commodities is that there is long trail of experience, starting in the past and ending today. But - as banks use to state lately - gains from the past are no guarantee for future gains. On the contrary; each and every conventional commodity is anchored in an unsustainable past and can by no means give reliable clues for a future that is headed by Sustainable Development. The trail for sustainable products and services has no past, it starts today and leads far into the future. Only, we don't know anything about that future. Keeping in mind what the Brundtland Report says: "Sustainable Development is development that meets the needs of the present without compromising the ability of future generations to meet their own needs" (World Commission on Environment and Development, 1987), we have the responsibility from now on to design products and services in the wake of issues which lie in the future, in front of us! It's a complete, revolutionary turning around of the way we used to think - and very challenging.

Products and services which have been conceived this way can be called Future Capable. Although not yet part of that future, they have the potential to fit in a future context. It will be clear that unsustainable product design, unsustainable raw materials, unsustainable processing and energy, next to substantial waste generation, will altogether lead to a product that is not Future Capable. That is a huge risk for the operations and investments of any company that would act in such a way. A producing company or developing lab will, on the contrary, try to the best of their knowledge and capabilities to become Future Capable as an organization.

But that is not easy and not immediately rewarding in terms of profit. Therefore, we will more often than not see some form of greenwashing popping up. There's all kinds of flavors, from smoothing some edges to sheer fraud, but always with the purpose to be perceived as "green". You have green petrol (it's toxic, carcinogenic and highly flammable), green apple perfume (green apples really don't have any perfume stuff) or natural soap (there is no soap tree on which that grows).

Unfortunately, many publications targeting a "green" consumer try to pick their grain as well. They start making product evaluations without having the technical knowledge to do so and without any real knowledge about environmental issues or Sustainable Development - except for the pure legal things, but those are always legging far behind reality. Thus is the consumer more or less left to himself in a no mans land.

This mustn't be, however. It is perfectly possible to select - or even develop - sustainable gauges. The starting point has to be to select or develop gauges for raw material sourcing, process technique selection and energy, product design, and finally the health and environmental impacts at use and after disposal. None of these can claim to be the ultimate complete tool, a "green meter", that gives you once and for all the mathematically exact ranking of whatever. Nature doesn't function like that, it's not a machine, and neither are we. But these tools can give us fairly reliable estimations.

Just two examples:

- The Eco-costs/Value Ratio (EVR) developed by the Technical University Delft, The Netherlands (http://www.ecocostsvalue.com). 
- The Eco-Footprint, originally developed in Canada, in the meantime in use in different forms (http://www.myfootprint.org)

When held against such sustainable gauges, actual solutions can be evaluated and be put in a priority ranking for further improvement. Compromises will have to be made and a time frame accepted: not every critical element can be instantly replaced, for very different reasons, such as unavailability of materials or processing, technical incompatibilities or financial constraints - or all of them together. There are many examples from the recent past.

- Until recently, fridges used to function on chlorinated compounds (CFC's) which are ozone depleting, persistent, toxic and carcinogenic. They have been exchanged for one or two less risky compounds - which could have been done since long. Nevertheless, 'less risky' is not 'good' and other solutions have to be developed.

- Hybrid cars mainly use two different engines, a combustion one and an electric one. They have low consumption and low emissions. But hybrids are neither the solution for the mobility problem, nor are they the ultimate green cars; they just feature the Best Available Technology (BAT) of the moment.

- Ecosurfactants are a class of washing agents from renewable raw materials, made via fermentation, at low temperature, low pressure and zero waste. They outperform both petrochemical and plant based surfactants on efficiency. But not all needs of detergent concepts can yet be covered.

- In almost each country there are organizations which defend consumer interests. But they are more often than not axed on quite superficial, practical and price issues and hardly on sustainable ones. They mostly take a Calimero standpoint and don't really try to mediate between consumers and industry to develop a common ground.

Because of the complexity of the issues, each market segment will have to develop its own models and time frames. These models will need frequent revisions to fit in a forever changing context. All of us will have to learn to operate in a very different context. Where we are now in a closed circuit, with proprietary knowledge and confidentiality issues, we will have to adhere to Open Access, validation and control by external parties and sharing of know-how. It seems that the idea of competition in the old sense is getting quite rusty in this changing world and asks rather for models based on communication and collaboration.

In the next chapter, we describe the elements and the backbone of such a model for washing and cleaning commodities as developed and used by Ecover, based on the above ideas.

\section{Ecover's "diamond" model}

Ecover is a medium sized, Belgium based company and is one of the foremost pioneers in developing and manufacturing washing and cleaning products with respect for the environment. It started off three decades ago by deleting environmentally troublesome ingredients (such as phosphates, alkyl phenol ethoxylates and the like) from standard frame formulas. This resulted in the so-called "No-code" (product doesn't contain such and doesn't contain so), which was communicated on the packaging.

Oleochemical based alternatives to petrochemicals were used wherever possible - there were not very many, 30 years ago. This black-or-white approach, though easy to understand 
by the consumer, did by no means automatically guarantee a satisfactory product performance. But such was the understanding of the post-hippie generation: a product was considered "environmental", or even worse, "natural" when it did not contain certain ingredients which were on a relatively vague blacklist. Over the years and in the wake of the appearance of a forever growing number of renewable raw materials, it was replaced by a more pragmatic approach, the in the meantime quite well known and respected "Ecover Concept".

Today, Ecover's environmental product profile is maximized to achieve market standard performance. If the balance of a basic set of criteria (price, performance, convenience, human safety, environmental profile) of a functional ingredient, is considered prone to improvement, an ingredient development project is set up, usually in cooperation with academic and/or industrial partners. This approach necessitates a quantitative tool to measure ingredient and product strengths and weaknesses and to allow a company wide evaluation of innovation progress. Ironically enough, a large part of the market where Ecover acquired sales strength over the last decade is reluctant to even try to understand the full story; yet they desire to make the best environmental purchase. They are looking for a simple approach or even some authority who can tell them what is right and what is wrong; as we learned however, there is no such situation in the real world. But some ecolabel schemes deliver exactly this pass/fail endorsement, without necessarily featuring a coherent product picture.

The challenge for Ecover therefore was to develop a model based on externally verifiable data, encompassing the largest part of the Ecover concept, yet easy to understand for the non-chemist and allowing almost instant appreciation of a product's profile, both within the Ecover company and among its consumers. By furthermore incorporating European ecolabel criteria into the model and having this model validated and controlled on a yearly basis by an independent third party (in this case the Belgian NPO Vinçotte Environnement) the Ecover "diamond" model (fig.1) has become a strong and difficult to dispute communication tool. It takes Ecolabel criteria to a higher level by incorporating criteria on ingredient sourcing and adhering to stricter standards with regard to environmental impact and leftover fate. The "Ecover diamond" model (thus named because of the diamond-like structure of its visualisation) can be considered as a self-declared environmental claim according to ISO 14021. Self-declarations are more often than not unreliable and untrustworthy, but here we have one that responds to strict external regulations and controls. An important requirement for environmental claims and their evaluation is their scientific basis, with only clearly referenced methods, calculations and standards.

The diamond model has proven to be a useful tool in product development, product benchmarking (comparing Ecover products with market references) and in communication. The Ecover diamond is the methodological translation of most of the Ecover environmental concept as it has been around for more than a decade. The procedure describing the diamond compilation also includes "focal drivers" mainly pertaining to qualitative criteria and to criteria which are hard if not impossible to assess for competing products. These focal drivers thus embody additional Ecover commitments not visualised in the diamond and often not communicated in any way. In this respect the diamond procedure has in fact become the written compilation of the Ecover concept. 


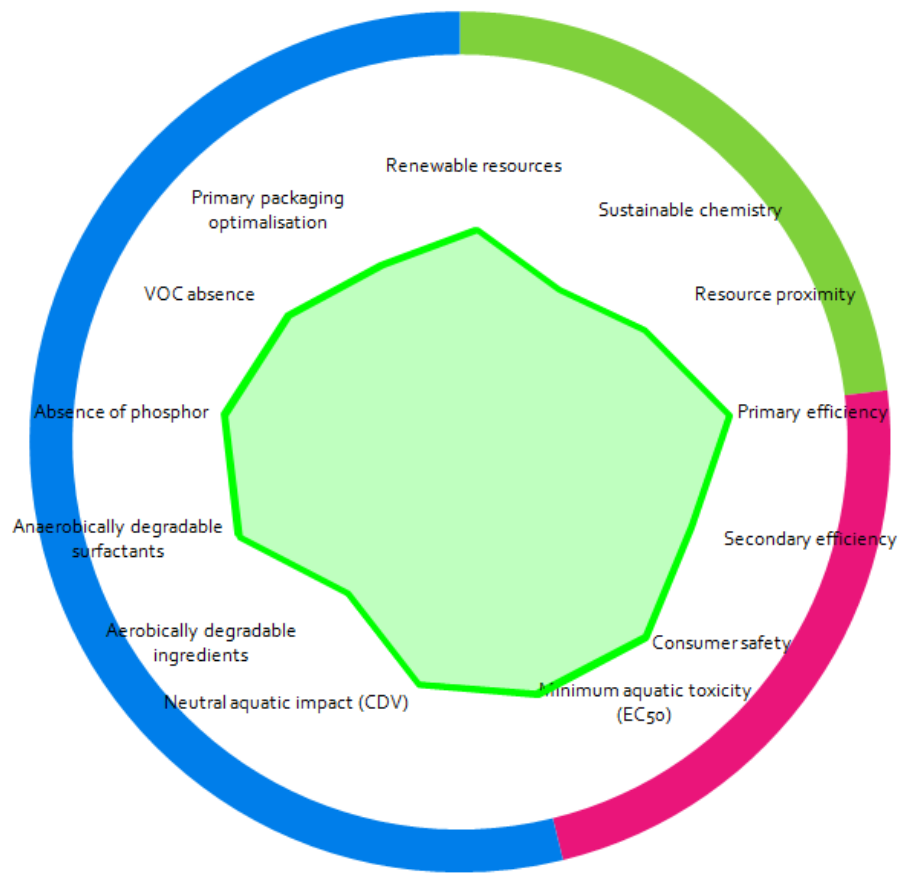

Fig. 1. Ecover diamond model with 13 axes distributed over 3 life cycle phases.

The model involves the total life cycle of a product, the Extraction Phase, the Usage Phase and the Absorption Phase. The latter phase is termed "Absorption" rather than the standard LCA "Disposal phase" terminology, to refer to a cradle-to-cradle, closed carbon loop, without persistent chemicals and without lasting ecosystem perturbation. It is visualized as a spidergram with 13 quantitative axes distributed over the three said phases.

The Extraction Phase involves Renewable Resources, Green Chemistry and Material Proximity. Renewable Resources are defined as animal, vegetable or microbial derived feedstocks, as opposed to water, mineral and petrochemical resources. This axis represents the percentage of renewable matter over the total organic dry matter of the end product and correlates very good with experimental $\mathrm{C}_{14}$ carbon dating results.

The Green Chemistry axis reflects Ecover's striving for efficient resource transformation at low temperature and pressure, without potential run away reactions or risk of explosion, while making use of chemicals currently considered as safe, with limited risk of undesirable by-product formation. The axis is calculated by a weighted sum of "green chemistry scores" across all ingredients over the total organic dry matter.

Resource Proximity covers the $\mathrm{CO}_{2}$ contribution of the complete product formula, from the source of the ingredient constituents, to the ingredient manufacturer, to the Ecover factory in Malle, taking into account the distance traveled by all individual ingredients and their transport mode.

The Usage Phase involves Primary Efficiency, Secondary Efficiency and Consumer Safety. 
The Primary Efficiency is the immediately perceivable performance of a product. This axis represents the percentage of "performance score", relative to a reference formula and determined according to EU Ecolabel standards.

Secondary Efficiency is the performance of the product at lower temperature (in automated appliance products) or a second performance attribute (such as speed of drying, gloss retention, ...), again relative to a reference formula.

Consumer Safety covers the use of surfactants that are safe for the user. Several attributing points towards consumer safety are defined. The absence of certain danger classes (e.g. corrosive, toxic, ...) attributes a percentage to the total score.

The Absorption Phase involves Aquatic Safety, Limited Aquatic Impact, Aerobically Degradable Ingredients, Anaerobically Degradable Surfactants, Phosphorus Absence, VOC Absence and Primary Packaging Optimisation.

Aquatic Safety covers the use of ingredients that are safe for the aquatic environment and is determined experimentally at Ecover as aquatic toxicity tests and expressed as a dose related $\mathrm{LC}_{50}$ quotient.

Limited Aquatic Impact is calculated as the Critical Dilution Volume (CDV), a concept developed within the EU ecolabel and expressing the theoretical amount of liters required to dilute a single product dose down to environmentally harmless concentrations, provided sewage treatment systems are in place.

Aerobic Biodegradability is an important and desirable property of any ingredient in washing and cleaning products. This diamond axis visualizes the amount of persistent chemicals in the product, i.e. the chemicals that are not inherently degradable by microorganisms when oxygen is present. An ingredient can be readily biodegradable, inherently biodegradable or persistent in aerobic conditions. This clearly differentiates the diamond model from ecolabel criteria.

Anaerobically Degradable Surfactants excludes surfactants which are not biodegradable in anaerobic conditions, i.e. in oxygen deprived environments should be avoided to the extent possible since aerobic conditions are not always the case, such as in many rivers, marine sediments or sewage sludge.

Phosphorus Absence documents possible amounts of phosphorus, which in the aquatic environment causes eutrophication. Hence, the use of phosphorus-based ingredients should be minimized.

The environmental relevance of Volatile Organic Carbons (VOC) is the contribution to indoor air pollution and smog formation.

The Primary Packaging axis aims at reducing this waste according to several references and assumptions.

For more detailed information on the Diamond Model, see at www.ecover.com (or specific URL).

\section{References}

Braungart M.\& McDonough, B. (2002). Cradle to Cradle: Remaking the Way We Make Things, North Point Press, New York. 
Carson, R. (1960). Silent Spring, First Mariner Books, ISBN 0-618-24906-0, edition 2002

Christakis, H.; Jantsch, E.\& Özbekhan, H. (1970). The Predicament of Mankind, Date of access 27/10/11, Available from:

http:/ / sunsite.utk.edu/FINS/loversofdemocracy/Predicament.PTI.pdf

Chua, J. (2007). Latin American Banana farmers sue over pesticides. In: TreeHugger, 27/10/11, Available from:

http://www.treehugger.com/files/2007/08/pesticide_lawsuit.php

Colruyt Group, 2010. Groep Colruyt ontwikkelt hybride trekker, press release 21/06/2010, Available from: http://www.colruytgroup.be/colruytgroup/static/energiebeleidhybride_be-nl.shtml

European Commission, 2000. Communication from the Commission of 2 February 2000 on the precautionary principle, Available from:

http://europa.eu/legislation_summaries/consumers/consumer_safety/132042_en. htm

Greenpeace, 2011. Turn VW away from the Dark Side. Press Campaign, Available from: http://www.vwdarkside.com/en

Kaufman F. (2010). The Food Bubble: How Wall Street starved millions and got away with it, Harper's Magazine, July 23, 2010.

Meadows, D.; Meadows, D.; Randers, J.\& Behrens III, W. (1972). The Limits to Growth. Universe Books, ISBN 0-87663-165-0, New York:

Nelson, S. (2008). Ethanol no longer seen as big driver of food price, Reuters Press Release 23/10/08, Available from: http://uk.reuters.com/article/2008/10/23/food-cornethanol-idUKN2338007820081023

US Census Bureau, 2011. World POPClock Projection, Available from : http://www.census.gov/population/popclockworld.html

Western Organisation of Resource Councils (WORC), 2007. Fact sheet October 2007

World Commission on Environment and Development, 1987. Our Common Future, Report of the World Commission on Environment and Development, Published as Annex to General Assembly document A/42/427, Development and International Cooperation: Environment, Available from:

http:// worldinbalance.net/intagreements/1987-brundtland.php 


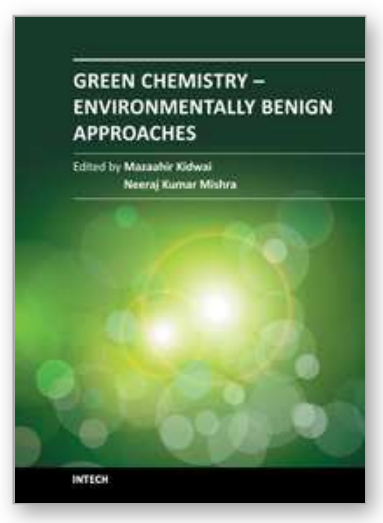

\author{
Green Chemistry - Environmentally Benign Approaches \\ Edited by Dr. Mazaahir Kidwai
}

ISBN 978-953-51-0334-9

Hard cover, 156 pages

Publisher InTech

Published online 23, March, 2012

Published in print edition March, 2012

Green chemistry is chemistry for the environment. It is really a philosophy and way of thinking that can help chemistry in research and production to develop more eco-friendly solutions. Green chemistry is considered an essential piece of a comprehensive program to protect human health and the environment. In its essence, green chemistry is a science-based non-regulatory and economically driven approach to achieving the goals of environmental protection and sustainable development. Combining the technological progress with environmental safety is one of the key challenges of the millennium. In this context, this book describes the environmentally benign approaches for the industries as well as chemical laboratories. In order to provide an insight into step change technologies, this book was edited by green organic chemists.

\title{
How to reference
}

In order to correctly reference this scholarly work, feel free to copy and paste the following:

Develter Dirk and Malaise Peter (2012). Greenwashing and Cleaning, Green Chemistry - Environmentally Benign Approaches, Dr. Mazaahir Kidwai (Ed.), ISBN: 978-953-51-0334-9, InTech, Available from: http://www.intechopen.com/books/green-chemistry-environmentally-benign-approaches/greenwashing-andcleaning

\section{INTECH}

open science | open minds

\section{InTech Europe}

University Campus STeP Ri Slavka Krautzeka 83/A 51000 Rijeka, Croatia Phone: +385 (51) 770447 Fax: +385 (51) 686166 www.intechopen.com

\author{
InTech China \\ Unit 405, Office Block, Hotel Equatorial Shanghai \\ No.65, Yan An Road (West), Shanghai, 200040, China \\ 中国上海市延安西路65号上海国际贵都大饭店办公楼 405 单元 \\ Phone: +86-21-62489820 \\ Fax: $+86-21-62489821$
}


(C) 2012 The Author(s). Licensee IntechOpen. This is an open access article distributed under the terms of the Creative Commons Attribution 3.0 License, which permits unrestricted use, distribution, and reproduction in any medium, provided the original work is properly cited. 